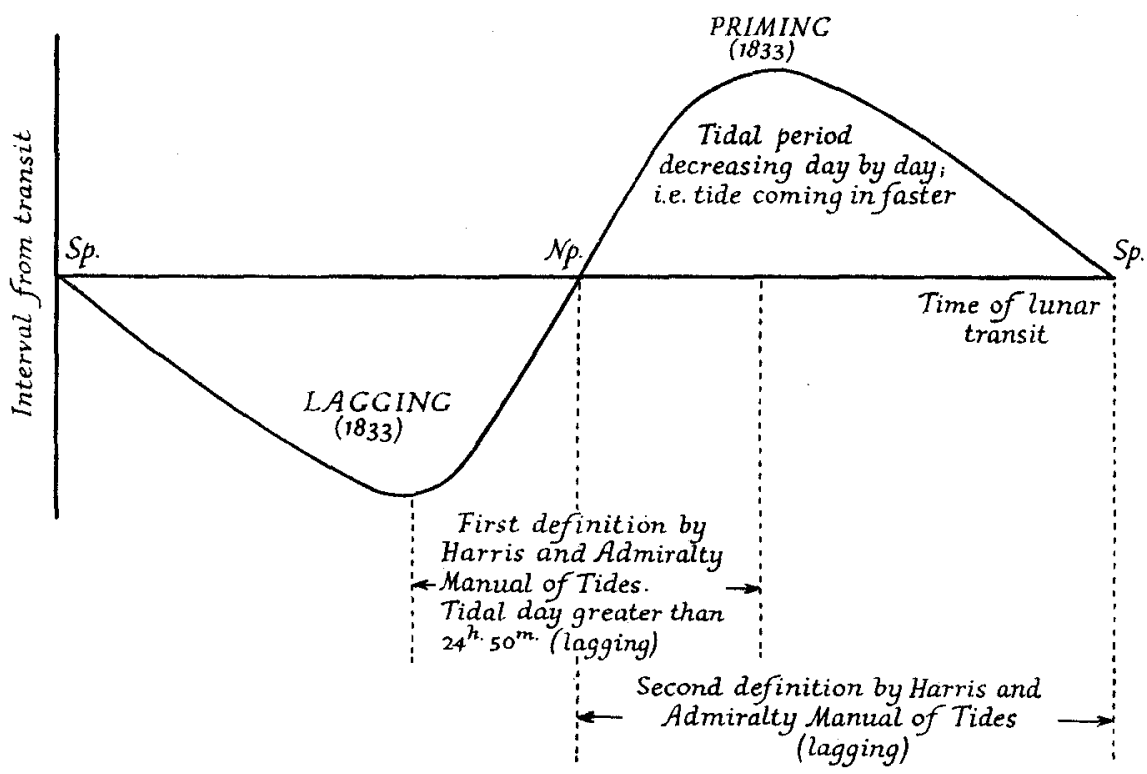

Fig. 1. Diagram showing variation and definitions.

The definitions given in the Admiralty Manual of Navigation (1922) and in one statement of the Admiralty Manual of Tides, also in the International Hydrographic Bureau's Hydrographic Dictionary, are the inverse of the original definitions. Harris's Manual is also incorrect and has two conflicting statements.

The simplest method of avoiding confusion would be to drop the terms, for they are never used in modern tidal exposition. The use of other terms and phrases will lead to similar confusion unless they are very lengthy. All the essential facts are given in the first paragraph of these notes.

\title{
The Size of Navigation Tables
}

IN his review of Sight Reduction Tables for Air Navigation (A.P. 3270) on page 98, Mr. J. B. Parker suggests that navigators might tolerate the disadvantage of tables with large intervals in the arguments. Mr. D. H. Sadler, Superintendent of H.M. Nautical Almanac Office, comments on this suggestion as follows:

Mr. Parker's suggestion is most intriguing. A substantial reduction in bulk would be possible, as the following table of approximate figures shows.

Interpolation for declination, and choice of assumed longitude, would be more difficult; the interpolation table for declination would either have to be larger or, more probably, coarser. The azimuth would have to be interpolated for declination. The actual values taken from the tables would not normally be greatly in error, though at an interval of $3^{\circ}$ in declination neglect of second difference in interpolation might give rise to an error of $2^{\prime}$ in the altitude. Errors will, however, arise in plotting: 
(a) about $4^{\prime}$ at a distance of $2^{\circ}$ due to neglect of curvature of the position line;

(b) about $2^{\prime}$ at a distance of $2^{\circ}$ for each degree error in azimuth;

(c) due to the limitation of the chart projection, unless very great care is taken (perhaps of the same order as $(a)$ ).

There will also be the practical inconvenience of long intercepts and widely spaced assumed positions.

Number of PAGes, IN DIFFERENT STYLes, ReQuired to COVER THE SAME SCOPE AS A.P. $3270(318+572$ PAGES $)$

\begin{tabular}{l|c|c|c|c}
\hline \multicolumn{1}{c|}{ Style } & \multicolumn{2}{|c|}{ Basic interval 2 } & \multicolumn{2}{c}{ Basic interval $3^{\circ}$} \\
\cline { 2 - 4 } & Vol. I & Vols. 2, 3 & Vol. I & Vols. 2, 3 \\
\hline $\begin{array}{l}\text { As A.P. 3270, same figures and } \\
\text { page size }\end{array}$ & 79 & 75 & 53 & 27 \\
$\begin{array}{c}\text { As A.P. I618 (A.N.T.s), same } \\
\text { figures and page size }\end{array}$ & 316 & $350^{*}$ & 165 & 108 \\
$\begin{array}{c}\text { As A.P. I618 but slightly more } \\
\text { compressed }\end{array}$ & 227 & $240^{*}$ & 106 & 96 \\
\hline
\end{tabular}

* These figures are very approximate.

Convenience, accuracy, bulk, ease of legibility, \&c., are conflicting factors in table design; and the ultimate decision between them must be with the user, who can alone appreciate their practical importance. 